\title{
Curriculum Setting and Pre-Clinical Dental Students' Stress Level
}

\author{
Priya C. Katwala \\ Swati K. Kulkarni \\ Nicholas M. Guy \\ Salome Zangaladze
}

\author{
Aleksandra Zak \\ Isaac Z. Stickney \\ University of New England \\ Stacey Dubois \\ University of New England \\ Yang Kang \\ University of New England \\ ykang@une.edu
}

\begin{abstract}
The first two years of dental school are commonly known to be the most stressful in a student's academic career. However, few studies consider both the pressures of dental school and their possible causes. In order to understand the relationship between the curriculum and its stressful effects on first (D1) and second-year (D2) dental students, a cross-sectional study was performed at the University of New England College of Dental Medicine (UNE-CDM) during the fall and spring semesters of the 2015-2016 academic year. Sixty-four D1 and sixty - three D2 dental students were asked to voluntarily complete an anonymous 27question survey regarding demographic characteristics and possible curriculumrelated stressors. Researchers utilized the modified Dental Environment Scale (DES) to rate the stress levels. This study revealed D2 students experienced more stress than D1 students overall. D2 students experienced more anxiety in their spring semester of their second year. In general, students who lived with their immediate family felt less stress. Students twenty-five and over experienced less stress than their younger classmates. The study provided valuable information regarding the current structure of the curriculum at a newly established dental school. This study could provide insight into curriculum-related stress among preclinical dental students, which could guide dental schools in making curricular changes to help alleviate stressors during particularly stressful semesters. Furthermore, the outcomes of this project could provide dental schools the information necessary to develop student support programs to help balance students' lives and intense course loads.
\end{abstract}

Katwala, Kulkarni, Guy, Zangaladze and Zak were students at the University of New England when this article was researched and written. 
Keywords: curriculum development, stress, education, academic environment, predental

\section{Introduction}

It is well known that dentistry is a high stress profession (Hoad-Reddick, 2003). Studying for dental classes demand an extraordinary amount of time most students have never experienced before (Garbee, 1980). Although most prospective dental students anticipate an intensive course load in dental school, oftentimes they are overwhelmed and surprised at the extent and reality of the difficulty when they begin their first year (D1). The second year (D2), however, becomes even more intense and difficult because these students have to deal with the foundational tasks that will comprise their future careers in dentistry, including a large number of clinical exams, patient interactions, and the National Board Dental Examination (NBDE). The workload of dental school combined with students' self-expectations causes great stress. A previous research has documented high levels of stress and burnout among dental students (Divaris, 2012). Students are constantly studying for their academic and clinical classes, which allows little time for relaxation and rest, resulting in further anxiety and stress levels. Excessive pressure and anxiety from school may cause students to regress in their clinical and general performance (Peretz, 1997), and further adversely affect one's general health (Lin, 1989; Thornton, 2004).

In the past decade, several studies have evaluated the stress of dental students. A longitudinal study conducted by Silverstein and Kritz-Silverstein showed an increase in stress in first year dental students throughout their dental education (Silverstein, 2010). Another study conducted by Rajab examined the levels and causes of stress among dental students at the University of Jordon (Rajab, 2001). While Silverstein's and Kritz-Silverstein's study mainly examined students' stress levels, Rajab's study focused on the stressors themselves. There have been only a few studies that consider both the pressures of dental school and its possible causes; even fewer analyze these in both D1 and D2 dental students. Through the examination of both the possible causes and degree of stress D1 and D2 dental students encounter, a better understanding is necessary, so proper modifications can be made to the curriculum (Alzahem, 2011).

One aspect dental schools must understand is that stress levels and their causes may vary based, in part, on where students are in the program (Newton, 1994). Research conducted in 2007 by Morse and Dravo noted most dental students start school with reasonably low levels of stress, which consistently increase throughout the duration of their dental education (Morse, 2007). Studies conducted on upper-level dental students shows they have an overall higher stress level than students at lower levels and they could benefit from lifestyle changes and programs to help manage these pressures (Sanders, 1999; Cohen, 1985; Goldstein, 1980). For example, Muirhead and Locker found students who had support from family, teachers, and friends handled pressure better than students who lacked such support systems (Muirhead, 2008). D1 dental students may feel stress because they are in a new environment, away from home, and concerned with developing relationships with fellow classmates and faculty. Previous research has shown students in these new environments experiencing stress may benefit from counseling and stress management programs (Grandy, 1988; Al-Sowygh, 2013). In contrast to D1 dental students, D2 students may feel more stress due to the immense amount of clinical work versus adapting to a new environment. Many D2 students are beginning to work with their first patients and may also be nervous about taking the board examinations. Research suggests that these findings are consistent for most dental school programs (Morse, 2007).

Journal of the Scholarship of Teaching and Learning, Vol. 18, No. 4, December 2018. josotl.indiana.edu 
new environment. Many D2 students are beginning to work with their first patients and may also be nervous about taking the board examinations. Research suggests that these findings are consistent for most dental school programs (Morse, 2007).

At the University of New England College of Dental Medicine (UNE CDM), dental students deal with challenges differently, depending on where they are in the program. In this newly established dental school, D1 dental students have 38 credits in fall semester and 36 credits of class work in spring semester. On the other hand, D2 dental students have three semesters. They have 40 credits of class work in the summer, 35 credits in the fall, and 35 credits in their spring semester. Another difference between the D1 and D2 dental classes at UNE CDM in the 20152016 academic year is the grading policies. D1 classes were graded as pass/ fail while the D2 classes were ranked with letter grades (A, B, C, D, E and F).

While dental students often worry about school, it is also important to note their concerns about entering the dental profession. Previous studies identify some of the major sources of student stress, such as insecurity regarding their future careers, not performing well on exams, fulfilling their clinical requirements, and receiving feedback from professors (Sekhon, 2015). Although different triggers induce stress in people in varying degrees, a multitude of factors could contribute to their stress levels. Accordingly, it can be difficult to identify specific sources of students' pressures regardless of where they attend dental school or at which year they are in their education.

Although there have been approximately nine dental schools established since 2008, no research has been conducted to evaluate students' levels of anxiety and influential factors at new dental schools. The purpose of this study is to measure stress levels of D1 and D2 students attending UNE CDM to determine if there is a relationship between stress levels of particular semesters in the first two years' curriculum. Analyzing the stress levels of dental students in different years of the program will hopefully give a better understanding of the causes and degree of stress students experience so curriculum changes or modifications can be considered.

\section{Methods}

This project was approved by the University of New England Institutional Review Board (IRB) (Project \#: 081215-002). Participants were informed if they chose to participate, not participate, or stop participation at any time would have no impact on their grades or standing in the dental program. Their answers were kept confidential and could not be identified in any way.

A cross-sectional study of stress levels of first-year and second-year dental students attending the University of New England College of Dental Medicine was conducted during the academic year of 2015-2016. The method for collecting data was through an online survey. One hundred twenty-seven subjects were asked to complete an anonymous twenty-seven-question survey at the end of their fall and spring semesters. The survey was only given to students in their first and second years, since those years include the didactic portion of the four-year program.

Sixty-four D1 and sixty-three D2 students were invited to complete the survey. The response rate was $84 \%$ for $\mathrm{D} 1$ and $93 \%$ for D2 students. The time allotted for the survey was between 10 and 15 minutes. This questionnaire was designed to measure dental-school-related stress. The questions selected for the survey were taken from the Dental Environment Scale (DES) (Garbee, 1980) and adjusted to fit the criteria for the student stress study at the UNE School of Dental Medicine based on the school curriculum.

The first nine questions of the questionnaire assessed demographic characteristics (e.g., age, gender, marital status, etc.) (see Table 1). Question \#3 addressed the student's science

Journal of the Scholarship of Teaching and Learning, Vol. 18, No. 4, December 2018. josotl.indiana.edu 
background prior to dental school. This question was selected to assess if a science background had an effect in alleviating stress. Question \#5 targeted students living in the New England area to assess the impact of attending school while living at or close to home. Question \#9 addressed students who had family commitments. Question \#10 inquired about students' stress level prior to dental school, which was used to exclude those participants with a history of high stress level to avoid confounding the results.

Table 1. Demographic Questions in the survey

\begin{tabular}{|c|c|c|c|c|}
\hline What is your gender? & Male & Female & Other & \\
\hline How old are you? & $\leq 25$ & $>25$ & & \\
\hline $\begin{array}{l}\text { What was your background in } \\
\text { undergraduate study? }\end{array}$ & $\begin{array}{l}\text { Biological } \\
\text { Sciences }\end{array}$ & Other & & \\
\hline What year are you in Dental School? & First-Year & Second-Year & & \\
\hline $\begin{array}{l}\text { Are you originally from the New } \\
\text { England area (Maine, New Hampshire, } \\
\text { Vermont, Massachusetts, Rhode Island } \\
\text { and Connecticut)? }\end{array}$ & Yes & No & & \\
\hline How often do you go home? & Daily & Weekly & $\begin{array}{l}\text { 3-4 times } \\
\text { per semester }\end{array}$ & $\begin{array}{l}0-2 \text { times } \\
\text { per semester }\end{array}$ \\
\hline $\begin{array}{l}\text { Does your immediate family live with } \\
\text { you? }\end{array}$ & Yes & No & & \\
\hline $\begin{array}{l}\text { What is your current relationship } \\
\text { status? }\end{array}$ & Single & $\begin{array}{l}\text { Long-term } \\
\text { Relationship }\end{array}$ & Married & \\
\hline Do you have kids? & Yes & No & & \\
\hline $\begin{array}{l}\text { Do you have a previous diagnosis of } \\
\text { anxiety or other psychological } \\
\text { problems (prior to dental school)? }\end{array}$ & Yes & No & & \\
\hline
\end{tabular}

Questions \#11-27 rated levels (0-3) of curriculum-related stress according to the modified Dental Environment Scale (DES) (Garbee, 1980; Muirhead, 2008) with "0-not stressful"; "1slightly stressful"; "2-moderately stressful"; and "3-very stressful". The survey was distributed online as to ensure availability to all students in a timely manner. The questionnaire was available for students to complete through the Blackboard Learn ${ }^{\mathrm{TM}}$ software in November 2015 and via www.SurveyMonkey.com in April 2016. The results were compiled into an Excel spreadsheet and statistically analyzed using SPSS software. 


\section{Results}

Comparison of sociodemographic characteristics

The sociodemographic characteristic results are shown in Figure 1. 79.03\% D2 students have a Biological Sciences undergraduate background, whereas the ratio for D1 is $70 \%$ (Figure 1A). In addition, more D2 students are from New England area (51.61\% for D2 vs $41.67 \%$ for D1), which implicates higher travelling home frequency (Figures 1A and 1B). As illustrated by Figure 1C, $75.81 \%$ D2 students are either married or with long-term relationship, comparing to $58.33 \%$ D1 students.

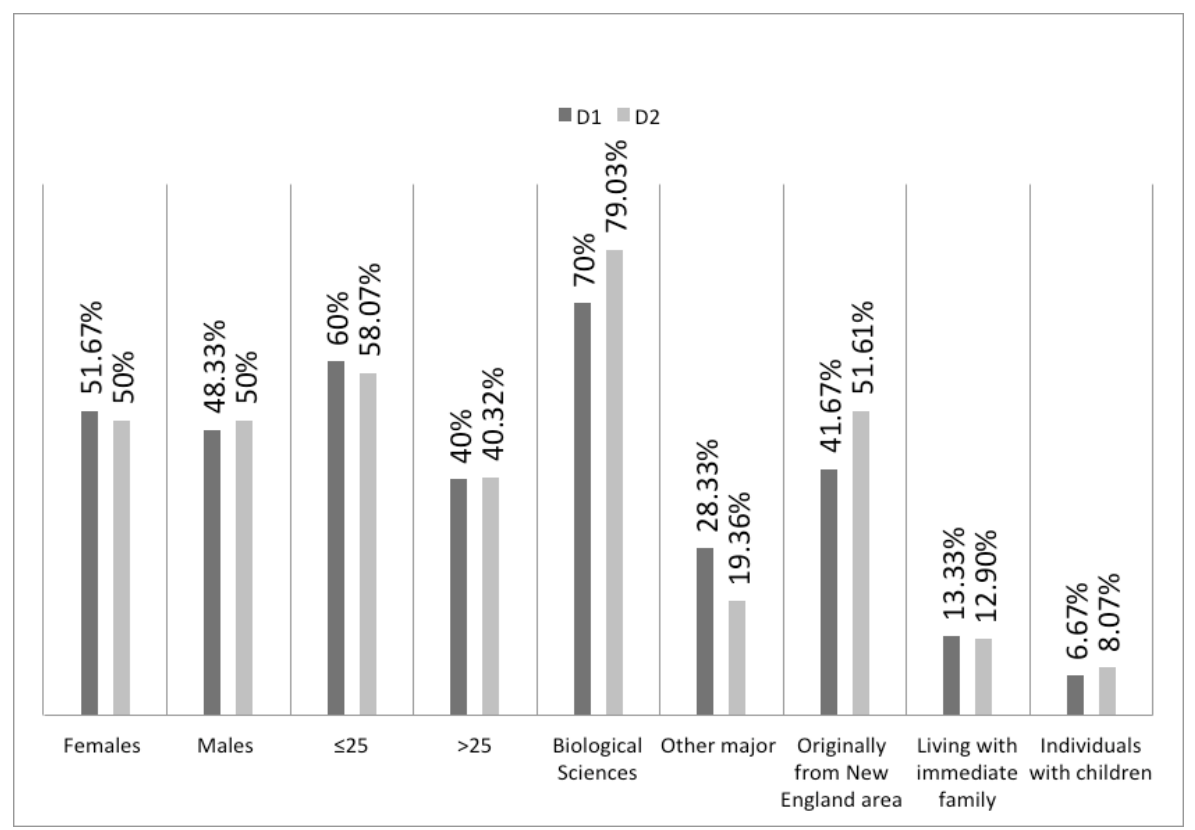

Figure 1A. Comparisons of sociodemographic characteristics of first- and second-year dental students at UNE-CDM are shown (D1=64 students; D2=63 students).

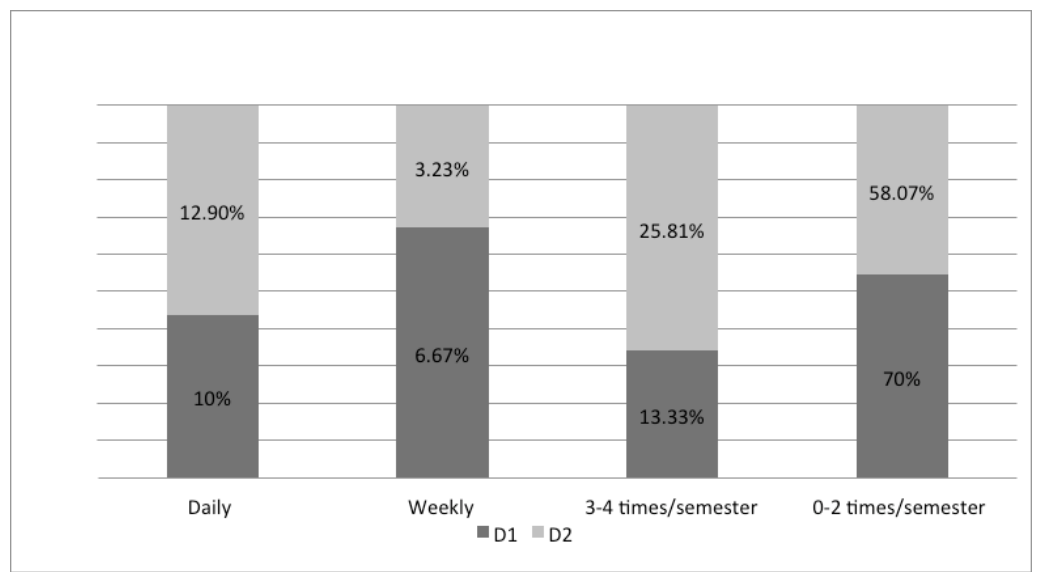

Figure 1B. First- (D1) and second-year (D2) dental students' frequency of traveling home during the Fall 2015 semester is shown (D1=64 students; D2=63 students). 


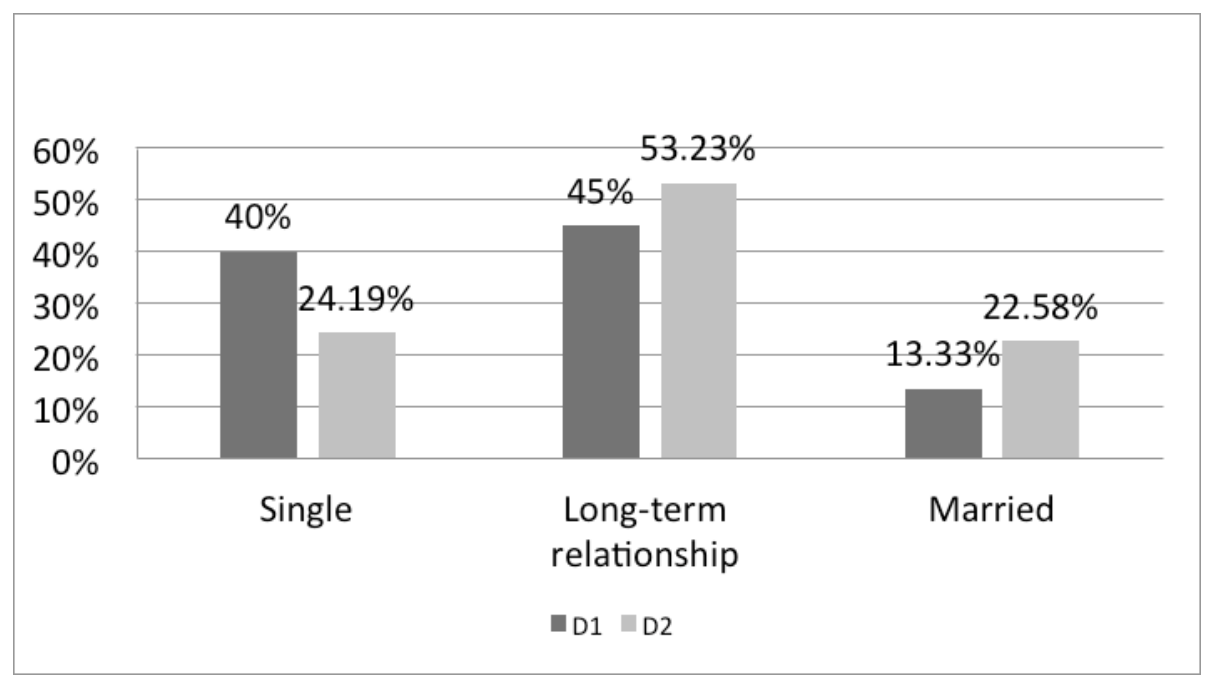

Figure 1C. The relationship status of first- (D1) and second-year (D2) dental students at the time of the Fall 2015 survey is shown (D1=64 students; D2=63 students).

Spring semester was significantly more stressful

The data collected from the survey given to first-year (D1) and second-year (D2) dental students indicate that D2 students are more stressed than D1 students overall. The spring semester was significantly more stressful for both years (see Table 2).

Table 2. Overall mean stress scores for first- (D1) and second-year (D2) dental students during the Fall 2015 and Spring 2016 terms are shown (D1=64 students; D2=63 students).

\begin{tabular}{|l|l|}
\hline Semesters & Mean Scores \\
\hline D1 Fall & 25.0577 \\
\hline D2 Fall & 27.5741 \\
\hline D1 Spring & 40.2917 \\
\hline D2 Spring & 40.4565 \\
\hline
\end{tabular}

Second year dental students (D2) experienced more anxiety

Multiple stress factors were evaluated from 2015 fall semester (see Table 3). It is notable students dealt with more difficulty in learning manual skills for simulation laboratory/clinical work (D1 mean, 1.549; D2 mean, 1.370) in their first semester of dental school. For questions 11-27, D2 students experienced more anxiety. The mean of the following research questions displayed this trend: stress from studying for examinations (D1 mean, 2.083; D2 mean, 2.387); stress from receiving grades (D1 mean, 1.683; D2 mean 2.097); amount of assigned homework (D1 mean 1.166; D2 mean 1.5); difficulty of non-clinical (didactic) classwork (D1 mean 1.833; D2 mean 2.193); competition with classmates (D1 mean 0.616; D2 mean 1.032); and inconsistency of feedback on work between different instructors (D1 mean 1.733; D2 mean 2.048). 
Table 3. The overall survey results comparing first- (D1) and second-year (D2) dental students from the 2015 Fall semester are depicted (D1=64 students; D2=63 students).

\begin{tabular}{|c|c|c|c|c|c|c|c|}
\hline Research Question & $\begin{array}{l}\text { Year in } \\
\text { School }\end{array}$ & $\begin{array}{c}\text { Not Stressful } \\
\text { (0) }\end{array}$ & $\begin{array}{c}\text { Slightly Stressful } \\
\text { (1) }\end{array}$ & \begin{tabular}{|c|}
$\begin{array}{c}\text { Moderately Stressful } \\
\text { (2) }\end{array}$ \\
\end{tabular} & \begin{tabular}{|c|} 
Very Stressful \\
(3) \\
\end{tabular} & Unanswered & MeanScore \\
\hline \multirow[b]{2}{*}{ Stress from studying for examination } & D1 & $3.33 \%$ & $20 \%$ & $36.67 \%$ & $38.33 \%$ & $1.67 \%$ & 2.08333 \\
\hline & D2 & $0 \%$ & $8.07 \%$ & $45.16 \%$ & $46.77 \%$ & $0 \%$ & 2.38709 \\
\hline \multirow[b]{2}{*}{ Stress from receiving grades } & D1 & $13.33 \%$ & $26.67 \%$ & $38.33 \%$ & $21.67 \%$ & $0 \%$ & 1.68334 \\
\hline & D2 & $6.45 \%$ & $20.97 \%$ & 29.032 & $43.55 \%$ & $0 \%$ & 2.09676 \\
\hline \multirow[b]{2}{*}{ Fear of failing courses } & D1 & $11.67 \%$ & $28.33 \%$ & $26.67 \%$ & $33.33 \%$ & $0 \%$ & 1.81666 \\
\hline & D2 & $16.13 \%$ & $29.03 \%$ & $20.97 \%$ & $33.87 \%$ & $0 \%$ & 1.72581 \\
\hline \multirow[b]{2}{*}{ Lack of time to do assigned simulation exercises } & D1 & $15 \%$ & $26.67 \%$ & $18.33 \%$ & $38.33 \%$ & $1.67 \%$ & 1.78332 \\
\hline & $\mathrm{D} 2$ & $9.68 \%$ & $29.03 \%$ & $32.26 \%$ & 29.032 & $0 \%$ & 1.80644 \\
\hline \multirow[b]{2}{*}{ Amount of assigned homework } & D1 & $35 \%$ & $23.33 \%$ & $26.67 \%$ & $13.33 \%$ & $1.67 \%$ & 1.16666 \\
\hline & D2 & $17.74 \%$ & $32.26 \%$ & $32.26 \%$ & $17.74 \%$ & $0 \%$ & 1.50000 \\
\hline \multirow{2}{*}{$\begin{array}{l}\text { Fear of being unable to catch up if I get behind } \\
\text { (simulation exercise, homework etc.) }\end{array}$} & D1 & $10 \%$ & $21.67 \%$ & $25 \%$ & $41.67 \%$ & $1.67 \%$ & 1.96668 \\
\hline & D2 & $6.45 \%$ & $20.97 \%$ & $32.26 \%$ & $40.32 \%$ & $0 \%$ & 2.06453 \\
\hline \multirow{2}{*}{$\begin{array}{l}\text { Getting sick (personal physical health) and } \\
\text { missing class }\end{array}$} & D1 & $21.67 \%$ & $23.33 \%$ & $30 \%$ & $25 \%$ & $0 \%$ & 1.58333 \\
\hline & $\mathrm{D} 2$ & $22.58 \%$ & $29.03 \%$ & $22.58 \%$ & $25.81 \%$ & $0 \%$ & 1.51612 \\
\hline \multirow[b]{2}{*}{ Difficulty of non-clinical (didactic) classwork } & D1 & $8.33 \%$ & $28.33 \%$ & $30 \%$ & $31.67 \%$ & $1.67 \%$ & 1.83334 \\
\hline & $\mathrm{D} 2$ & $3.23 \%$ & $14.52 \%$ & $41.94 \%$ & $40.32 \%$ & $0 \%$ & 2.19355 \\
\hline \multirow{2}{*}{$\begin{array}{l}\text { Difficulty learning manual skills for simulation } \\
\text { laboratory/clinical work }\end{array}$} & D1 & $18.33 \%$ & $28.33 \%$ & $33.33 \%$ & $20 \%$ & $0 \%$ & 1.54999 \\
\hline & D2 & $17.74 \%$ & $38.71 \%$ & $32.26 \%$ & $11.29 \%$ & $0 \%$ & 1.37096 \\
\hline \multirow[b]{2}{*}{ Difficulty in learning clinical procedures } & D1 & $21.67 \%$ & $36.67 \%$ & $25 \%$ & $15 \%$ & $1.67 \%$ & 1.31667 \\
\hline & $\mathrm{D} 2$ & $17.74 \%$ & $40.32 \%$ & $32.26 \%$ & $9.68 \%$ & $0 \%$ & 1.33870 \\
\hline \multirow[b]{2}{*}{ Competition with classmates } & D1 & $58.33 \%$ & $23.33 \%$ & $16.67 \%$ & $1.67 \%$ & $0 \%$ & 0.61668 \\
\hline & D2 & $35.48 \%$ & $37.10 \%$ & $16.13 \%$ & $11.29 \%$ & $0 \%$ & 1.03225 \\
\hline \multirow[b]{2}{*}{ Lack of time for relaxation } & D1 & $10 \%$ & $31.67 \%$ & $20 \%$ & $38.33 \%$ & $0 \%$ & 1.86666 \\
\hline & D2 & $8.07 \%$ & $20.97 \%$ & $32.26 \%$ & $38.71 \%$ & $0 \%$ & 2.01614 \\
\hline \multirow{2}{*}{$\begin{array}{l}\text { Discrimination due to socioeconomic status, } \\
\text { race or ethnic group, or sexual orientation }\end{array}$} & D1 & $78.33 \%$ & $15 \%$ & $3.33 \%$ & $1.67 \%$ & $1.67 \%$ & 0.26667 \\
\hline & D2 & $91.94 \%$ & $4.84 \%$ & $1.61 \%$ & $1.61 \%$ & $0 \%$ & 0.12904 \\
\hline \multirow{2}{*}{$\begin{array}{l}\text { Stress from attending a newly established dental } \\
\text { school (changes in faculty and curriculum, etc.) }\end{array}$} & D1 & $25 \%$ & $41.67 \%$ & $20 \%$ & $13.33 \%$ & $0 \%$ & 1.21666 \\
\hline & D2 & $17.74 \%$ & $32.26 \%$ & $33.87 \%$ & $16.13 \%$ & $0 \%$ & 1.48387 \\
\hline \multirow{2}{*}{$\begin{array}{l}\text { Inconsistency of feedback on your work } \\
\text { between different instructors }\end{array}$} & D1 & $10 \%$ & $33.33 \%$ & $30 \%$ & $26.67 \%$ & $0 \%$ & 1.73334 \\
\hline & D2 & $3.23 \%$ & 24.194 & $37.10 \%$ & $35.48 \%$ & $0 \%$ & 2.04840 \\
\hline \multirow[b]{2}{*}{ Rules and regulations of the school } & D1 & $43.33 \%$ & $31.67 \%$ & $10 \%$ & $15 \%$ & $0 \%$ & 0.96667 \\
\hline & $\mathrm{D} 2$ & $30.65 \%$ & $48.39 \%$ & $12.90 \%$ & $8.07 \%$ & $0 \%$ & 0.98388 \\
\hline \multirow[b]{2}{*}{ Financial problems } & D1 & $18.33 \%$ & $26.67 \%$ & $28.33 \%$ & $25 \%$ & $1.67 \%$ & 1.58333 \\
\hline & D2 & $19.36 \%$ & $19.36 \%$ & $27.42 \%$ & $33.87 \%$ & $0 \%$ & 1.75806 \\
\hline
\end{tabular}

First-year dental students living with their immediate family were less stressed

ANOVA analysis of the 2015 fall semester suggests during the first term, first-year dental students living with their immediate family were less stressed. P-value equals to 0.005 may be due to the fact that only six students reported living with their immediate family, while forty-six students were not living with immediate family (see Table 4). 
Table 4. ANOVA statistical analysis of the sociodemographic characteristics during fall 2015 semester for first-year (D1) dental students is shown (D1=64 students). D1 students living with their immediate family members compared to those living without family was statistically significant.

\begin{tabular}{|c|c|c|c|c|c|}
\hline \multicolumn{6}{|c|}{ ANOVA } \\
\hline & $\begin{array}{l}\text { Sum of } \\
\text { Squares }\end{array}$ & $\mathrm{df}$ & Mean Square & $\mathrm{F}$ & Sig. \\
\hline 1= Female, $2=$ Male & 7.647 & 30 & .255 & 1.004 & .506 \\
\hline $1=$ Younger, $2=$ Older & 7.077 & 30 & .236 & .862 & .652 \\
\hline $\begin{array}{l}\text { 1= Biological Science, } 2= \\
\text { Other }\end{array}$ & 33.090 & 30 & 1.103 & .646 & .866 \\
\hline $\begin{array}{l}\text { 1=New England, } 2= \\
\text { Other states }\end{array}$ & 5.558 & 30 & .185 & .576 & .918 \\
\hline $\begin{array}{l}\text { 1=Daily, } 2=\text { Weekly, } 3=3- \\
4 \text { times, } 4=0-2 \text { times }\end{array}$ & 35.833 & 30 & 1.194 & 1.905 & .064 \\
\hline $\begin{array}{l}\text { 1=Family with you, } \\
\text { 2=Family not with you }\end{array}$ & 4.308 & 30 & .144 & 3.015 & .005 \\
\hline $\begin{array}{l}\text { 1=Single, } 2=\text { Long-term } \\
\text { relationship, } 3=\text { Married }\end{array}$ & 15.173 & 30 & .506 & 1.118 & .401 \\
\hline 1=Have kids, $2=$ No kids & 1.577 & 30 & .053 & .883 & .630 \\
\hline
\end{tabular}

Older students are less stressed in their second-year dental school study

During the 2016 spring semester, twenty-two D2 students were 25 years old or younger, while twenty-four students reported being older. ANOVA analysis indicates students older than 25 years were less stressed $(\mathrm{p}<0.005)$ (see Table 5). No significant difference was found for the D1 sociodemographic characteristics during the spring semester. 
Table 5. ANOVA statistical analysis of the sociodemographic characteristics during the Spring 2016 semester for second-year (D2) dental students is shown (D2=63 students). Difference in age ( $\leq 25$ or $>25$-years-old) displayed a statistically significant difference.

\begin{tabular}{|c|c|c|c|c|c|}
\hline \multicolumn{6}{|c|}{ ANOVA } \\
\hline & $\begin{array}{l}\text { Sum of } \\
\text { Squares }\end{array}$ & df & $\begin{array}{l}\text { Mean } \\
\text { Square }\end{array}$ & $\mathrm{F}$ & Sig. \\
\hline What is your gender? & 4.638 & 25 & .186 & .557 & .917 \\
\hline How old are you? & 9.312 & 25 & .372 & 3.438 & .003 \\
\hline $\begin{array}{l}\text { What was your background in } \\
\text { undergraduate study? }\end{array}$ & 4.993 & 25 & .200 & 1.410 & .218 \\
\hline $\begin{array}{l}\text { Are you originally from } \\
\text { the New England area } \\
\text { (Maine, New Hampshire, } \\
\text { Vermont, Massachusetts, } \\
\text { Rhode Island, and } \\
\text { Connecticut)? }\end{array}$ & 5.500 & 25 & .220 & .733 & .771 \\
\hline How often do you go home? & 26.540 & 25 & 1.062 & 1.473 & .190 \\
\hline $\begin{array}{l}\text { Does your immediate family } \\
\text { live with you? }\end{array}$ & 3.717 & 25 & .149 & 1.983 & .061 \\
\hline $\begin{array}{l}\text { What is your current } \\
\text { relationship status? }\end{array}$ & 13.913 & 25 & .557 & 1.391 & .227 \\
\hline Do you have kids? & 2.652 & 25 & .106 & 2.122 & .045 \\
\hline
\end{tabular}

\section{Discussion}

In the 2015-2016 academic year at UNE CDM, D1s are evaluated on a pass/fail system for all courses. The D2s, on the other hand, received a graded transcript with a calculated Grade Point Average (GPA) for all courses since the start of their academic career. Grades and GPAs allow for students to be evaluated on a scale; the higher the grade and GPA one receives, the more successful they are perceived to be. The GPA system reflects how well a student performs on examinations and, inadvertently, how knowledgeable he or she is. Typically, the more one studies and reviews examination materials, the more likely the student will excel and do well on examinations. Since D2s are evaluated on a GPA system, they are more inclined to become stressed from studying for an examination and receiving grades. Conversely, D1s had a lower mean score for stress for these two categories. This is most likely because there is no pressure to earn a high grade or GPA. D1s merely have to "pass" each course. To receive a "pass," D1s must receive an average of 69.5 or 
above out of 100 for all examinations in each course. Since letter grades are not given, there may be a lack of motivation to receive the highest grade, producing less anxiety for D1s to study extensively or receive good grades.

The grades and GPAs D2s receive not only determine individual success but also provide a means to compare students. As students near graduation from dental school, they must decide which path they want to pursue, whether it is to specialize, complete a general residency, work for a corporate dental company, open a new practice or work as an associate in private practice. Hiring personnel or institutions that review newly graduated dentists' resumes need to distinguish one candidate from another. Although portfolios are now being used to provide a more holistic overview of a student, GPAs still allow students to be compared with one another. Therefore, another stress D2s face more than D1s, is "competition with classmates," D2s compete to receive the best grades so they can become better candidates for any post-graduate path they choose. In addition, another difference in the stress levels between D1s and D2s is that D2s have the additional stress of studying and taking part I of the National Board of Dental Examination (NBDE) at the end of the spring semester.

D2s also had a higher mean score for stress related to the "amount of assigned homework" and "difficulty of non-clinical (didactic) classwork." The didactic courses in dental school are often overwhelming with the amount of material presented in a short time span. Although homework is not graded for either D1s or D2s, most of the time assigned homework involves reading the textbooks for more in-depth information regarding topics covered in classes. Thus, completing homework helps with studying and getting a better understanding of the material which would hopefully result in superior grades for D2s.

D2s also had a much higher mean score for stress related to the category "inconsistency of feedback on your work between different instructors." UNE CDM is a new dental school that started in 2013 and, as with any developing program, changes are constantly occurring in efforts to improve the school's quality. UNE CDM has student evaluations completed for each course every semester and faculty respond making changes as needed. As D2s experienced some inconsistency with instructors when receiving feedback about their clinical work in simulation clinic, the D1s' faculty were calibrated to provide more consistent feedback, producing less stress for D1s.

On the other hand, D1s expressed more stress than D2s in "Difficulty learning manual skills for simulation laboratory/clinical work". This could be due to the fact that, in general, during the first year of dental school students are first learning manual dexterity skills and feel more pressure to achieve. On the other hand, D2 students have already acquired and honed many manual skills and therefore may feel more comfortable.

This study has some inherent limitations. The survey administered to students was sent via email. In addition, an announcement was made in class to inform students of the purpose of the study. Students may have completed the survey just for the sake of completion. Yet another factor to consider is a change in personal life circumstances. Some students became engaged, some got married, and some had pregnant spouses during the transition of the fall to the spring semesters, which may have influenced stress levels since these factors typically induce more stress (Sanders, 2002; Story, 2004).

Journal of the Scholarship of Teaching and Learning, Vol. 18, No. 4, December 2018. josotl.indiana.edu 


\section{Conclusion}

Stress has long been associated with adverse effects on one's health and can stem from a multitude of factors. Stress from social, psychological, and physiological environments all affect the wellbeing of an individual. Students in dental school must handle a rigorous academic course load, learn manual dexterity skills in simulation courses, and face challenging social and dental clinical experiences in patient clinics. Also, while academics may trigger stress, experiencing stress may have a negative impact on academic performance.

This study provided valuable information regarding the current curriculum structure at UNE CDM and how much stress students experienced. Project outcomes indicated D2 students experience more stress overall in comparison to D1s, and spring semester is much more stressful than fall semester. Also noted was that students living with immediate family and older students handle stress better.

The results of this study provided insight into curriculum-related stress of pre-clinical dental students in a newly established dental school. As advised by this research, the following curriculum modifications were made to help alleviate particularly stressful semesters. In 20152016 academic year, the course "Pediatric Dentistry" was in the summer semester and the course "Endodontics" was in the fall. In 2016-2017 academic year, those two D2 courses were swapped and upped the "Endodontics" course from 8 credit hours to 12 credit hours since students needed more time per week to acquire knowledge and practice their hand skills. In addition, another eightcredit-course for D2 students in 2015-2016 fall semester, which includes multiple medical disciplines, was divided into two courses (one three-credit-course in the summer semester and one five-credit-course in the fall semester) in 2016-2017 academic year to help students better balance their lives and intense course load.

Future directions of this study could be to conduct survey at some other new dental schools to compare the student stress level with that of the UNE College of Dental Medicine, especially dental schools that require students to take the National Board of Dental Examination part I at the end of the first year as opposed to the end of the second year.

\section{Acknowledgments}

This study was supported by the corresponding author's (Dr. Yang Kang) Scholarship of Teaching and Learning in the 2015 2016 academic year by the UNE Center for the Enrichment of Teaching and Learning. The authors gratefully acknowledge Dr. Susan Hillman for guidance and inspiring diligence, and Mr. Karl Carrigan for technology management.

We also would like to thank UNE CDM administrators for school encouragement and student support services. In addition, we extend our appreciation to Student Academic Success Center of the University of New England for student writing assistance.

\section{References}

Al-Sowygh, Z. H. Academic distress, perceived stress and coping strategies among dental students in Saudi Arabia. The Saudi dental journal. 2013; 25(3): 97-105.

Alzahem, A. M., Van der Molen, H. T., Alaujan, A. H., Schmidt, H. G., \& Zamakhshary, M. H. Stress amongst dental students: a systematic review. European Journal of Dental Education. 2011; 15(1): 8-18.

Journal of the Scholarship of Teaching and Learning, Vol. 18, No. 4, December 2018. josotl.indiana.edu 
Cohen, S., \& Wills, T. A. Stress, social support, and the buffering hypothesis. Psychological bulletin. 1985; 98(2): 310.

Divaris, K., Polychronopoulou, A., Taoufik, K., Katsaros, C., \& Eliades, T. Stress and burnout in postgraduate dental education. European Journal of Dental Education. 2012; 16(1): 35-42.

Garbee, W. H., Zucker, S. B., \& Selby, G. R. Perceived sources of stress among dental students. The Journal of the American Dental Association. 1980; 100(6): 853-857.

Goldstein, M. B. Interpersonal support and coping among first-year dental students. Journal of dental education. 1980; 44(4): 202-205.

Grandy, T. G., Westerman, G. H., Lupo, J. V., \& Combs, C. G. Stress symptoms among third-year dental students. Journal of dental education.1988; 52(5), 245-249.

Hoad-Reddick, G., \& Potter, S. The integration of counselling with tutorial support for dental students. International Journal of Health Promotion and Education. 2003; 41(4): 101-107.

Lin, Nan, and Walter M. Ensel. "Life stress and health: Stressors and resources." American Sociological Review. 1989; 382-399.

Morse, Z., \& Dravo, U. Stress levels of dental students at the Fiji School of Medicine. European Journal of Dental Education. 2007; 11(2): 99-103.

Muirhead, V., \& Locker, D. Canadian dental students' perceptions of stress and social support. European journal of dental education. 2008; 12(3): 144-148.

Newton, J. T., Baghaienaini, F., Goodwin, S. R., Invest, J., Lubbock, M., \& Marouf, S. N. Stress in dental school: a survey of students. Dental update. 1994; 21(4): 162-164.

Peretz, B., Rosenblum, A., \& Zadik, D. Stress levels and related variables among dental students in Jerusalem, Israel. European Journal of Dental Education. 1997;1(4): 162-166.

Rajab, L. D. (2001). Perceived sources of stress among dental students at the University of Jordan. Journal of dental education. 2001;65(3), 232-241.

Sanders, A. E., \& Lushington, K. Sources of stress for Australian dental students. Journal of dental education. 1999; 63(9): 688-697.

Sanders, Anne E., and Kurt Lushington. "Effect of perceived stress on student performance in dental school." Journal of dental education 66.1 (2002): 75-81.

Sekhon, T. S., Grewal, S., Gambhir, R. S., \& Sharma, S. Perceived sources of stress among dental college students: An Indian perspective. European Journal of General Dentistry. 2015; 4(3): 121.

Silverstein, S. T., \& Kritz-Silverstein, D. A longitudinal study of stress in first-year dental students. Journal of dental education. 2010; 74(8): 836-848.

Story, Lisa B., and Thomas N. Bradbury. "Understanding marriage and stress: Essential questions and challenges." Clinical psychology review 23.8 (2004): 1139-1162.

Thornton, L. J., Stuart-Buttle, C., Wyszynski, T. C., \& Wilson, E. R. Physical and psychosocial stress exposures in US dental schools: the need for expanded ergonomics training. Applied ergonomics. 2004; 35(2): 153-157. 